\title{
Digital technologies for launching innovative medications to the pharmaceutical market
}

\author{
Andrey Porokhnenko ${ }^{1}$ and Ekaterina Sapozhnikova ${ }^{1 *}$ \\ ${ }^{1}$ Vyatka State University, Moskovskaya str., 36, Kirov, 610000, Russia
}

\begin{abstract}
In modern conditions, the methods of bringing drugs to the pharmaceutical market has significant differences from other segments of the economy due to the following factors: the social significance of drugs that directly affect the quality of life and health of the population, the inability to refuse the use of drugs, the presence on the market of three groups of consumers - patients, doctors and the state represented by hospitals and the Ministry of health, legislative restrictions in the methods of marketing activity, a greater share of the presence of foreign multinational pharmaceutical companies, the specifics of the methods of bringing innovative drugs to the market. In order to quickly adapt to the everchanging environment and achieve the objectives, pharmaceutical companies use different methods for launching new products, which demonstrate different degrees of efficiency, levels of implementation, and speed of obtaining the desired result. Increasing competition on the pharmaceutical market between medication manufacturers and the battle for the consumer should be based on the active introduction of digital technologies and a rational combination of methods of bringing innovative drugs.
\end{abstract}

\section{Introduction}

All his life a person lives in the surrounding information environment. From early childhood to old age there is a process of perception, processing and response to the received information incentives. The rapid development of modern market relations leads to more data for both consumers and producers of goods and services. The active development and implementation of "digital technologies" in essence denoting the Internet, mobile phones and all other means of collecting, storing, analyzing and exchanging information in digital form is a new stage in the transmission of information.

The number of Internet users worldwide increased from 1 billion in 2005 to 3.2 billion in 2015, the number of SIM cards issued for mobile phones exceeded the population of the Earth. This broad penetration of digital technologies is considered as the fourth industrial revolution, the so-called "industry 4.0". According to PWC specialists, THIS concept is characterized by the following features:

1. "digitalization and integration of vertical and horizontal value chains»;

2. "digitalization of products and services»;

\footnotetext{
*Corresponding author: gasmin.87@mail.ru
} 
3. "digitalization of business models and client access".

Large - scale application of digital technologies in modern economic conditions has led to the emergence of the concept of "digital economy" and "digitalization of the economy." According to a report by Boston Consulting Group, the share of the digital economy in Russia in 2016 amounted to $2.1 \%$ of GDP, an increase of 1.3 times over the past 5 years. The interindustry effect of digital technologies has increased by 5.5 times since 2010: from 5 to 27.7 trillion rubles. By the number of Internet users, the Russian Federation has taken a leading position in Europe. In the message of Russian President Vladimir Putin The Federal Assembly from 01.12.2016 is offered "to start the large-scale system program of development of new economic generation, so-called digital economy". The active development of digital technologies is also mentioned in most documents of the Government of the Russian Federation, in the form of approved Concepts of short-term and long-term socio-economic development. The main points of growth in these documents are: 3D printing, robotics, the Internet of things, cloud computing, modeling and forecasting, digital processing of large amounts of information.

In order to achieve short-term results in the next two years, the so-called "quick wins", when using digital technologies, the following areas are proposed:

- development of e-Commerce platforms;

- selling of insurance policies via the Internet;

- accounting for alcohol sales online via the Internet;

- prescriptions in electronic form;

- accounting for online sales of medicines;

- introduction of electronic legal address;

- introduction of the electronic register of patents for rental apartments;

- digital archive;

- digital signature.

The development of digital technologies brings undoubted economic benefits not only to government agencies, companies producing goods and services, but also to the population (table 1).

Table 1. Benefits of digitalization of the economy.

\begin{tabular}{|c|c|c|}
\hline Government & Company & Consumer \\
\hline $\begin{array}{l}\text { - improving administration } \\
\text { efficiency (taxes, costs, } \\
\text { data collection and } \\
\text { planning); } \\
\text { - savings on document } \\
\text { management; } \\
\text { - reducing the number of } \\
\text { officials; } \\
\text { - improving access of the } \\
\text { population to control }\end{array}$ & $\begin{array}{l}\text { - increase of production and } \\
\text { sales efficiency; } \\
\text { - increase of labor } \\
\text { productivity; } \\
\text { - the globalization of } \\
\text { business; } \\
\text { - reducing the number of } \\
\text { employees; } \\
\text { - simplification of reporting } \\
\text { to the state; } \\
\text { - online control }\end{array}$ & $\begin{array}{l}\text { - improving the quality of } \\
\text { goods and services; } \\
\text { - increased competition } \\
\text { and lower prices; } \\
\text { - the emergence of new } \\
\text { products and services; } \\
\text { - the emergence of new } \\
\text { jobs; } \\
\text { - improving access to } \\
\text { public services }\end{array}$ \\
\hline
\end{tabular}

The main purpose of the marketing activity of the company is to increase sales and profit growth, and this can be achieved with the qualitative and quantitative improvement of communication with the buyer. The increasing role of the process of modern digital communication between the consumer and the manufacturer forces to perform the following tasks as efficiently as possible [1]:

- to inform about new products, their features and prices,

- to convince the consumer of the advantages of this product and brand, 
- force the buyer to act, that is, to actively buy to use this product,

- improve the service associated with the operation of the goods,

- encourage consumers to leave feedback on the product.

Digital marketing technologies play a special role in bringing innovative products to market. During this period of the product life cycle, it is necessary to convey relevant information to the maximum number of potential consumers, teach them how to use this product correctly, get the first mass feedback during operation and, if necessary, make changes in production. Given the level of implementation of digital devices among the population to achieve all these tasks allows the active use of digital technologies [2].

One of the important features of innovative products can be the technical complexity of their operation during the development of the consumer. For example, a new computer program will clearly cause initial difficulties for users, which can significantly limit sales when it appears on the market. Innovative products are increasingly working not on the principle of "used and forgotten", and require first to remember how to operate this product - "remembered as used and forgotten".

New drugs, being an innovative product that can be used at home, also have a number of features:

- limited shelf life,

- compliance with storage rules,

- the accuracy of the instructions for use or doctor's appointments,

- the possibility of adverse events and complications in the reception, which requires a second visit to the doctor.

Thus, one of the tasks of the marketing service in bringing innovative medicines to the pharmaceutical market is the constant exchange of information between the patient and the health professional about the regularity of the use of medicines [3]. Refusal or noncompliance with the requirements of the use of drugs causes serious harm to the treatment process, only in the United States for the year for this reason, about 125,000 people die, the annual cost of the medical American community to solve this problem is up to 295 billion dollars. In 2017, the us food and drug administration (FDA) authorized the use of Abilify MyCite, which was the first to use the "digital drug tracking system" [4]. Inside the tablet is built-in sensor consisting of safe for the human body copper, magnesium and silicon. Gastric juice activates the "mini-transmitter" and the signal is sent to a special device attached to the body, and then to the patient's smartphone. Subsequent access to the data on the cell phone is opened for the doctor and relatives. Experts expect that the use of such devices in the future will be used for any medication.

The launching of expensive innovative drugs into the pharmaceutical market requires constant control over the correctness and timeliness of their use. Strict implementation of doctor's prescriptions allows to achieve maximum efficiency of treatment and improvement of quality of life [5]. To achieve these goals, drug manufacturing companies in the Russian Federation have been actively using such methods of bringing to the pharmaceutical market as schools for patients using digital technologies in their marketing activities [6]. The exercise of such advance, as a rule, is conducted through educational grants from patient organizations. 
Table 2. Methods of launching of innovative medicines to the pharmaceutical market of the Russian Federation in different periods.

\begin{tabular}{|c|c|c|c|c|}
\hline Methods & $\begin{array}{l}\text { To } 1995 \text { year } \\
\text { (Federal law } \\
\text { "On } \\
\text { advertising») }\end{array}$ & $\begin{array}{l}\text { 1995-1998 } \\
\text { (signing of } \\
\text { the AIPM } \\
\text { code in the } \\
\text { first edition) }\end{array}$ & $\begin{array}{c}\text { 1998-2013 } \\
\text { (changes in the } \\
\text { Federal law "On } \\
\text { the basis of } \\
\text { health protection } \\
\text { in Russia») }\end{array}$ & $\begin{array}{c}\text { From } 2013 \\
\text { year to the } \\
\text { present time }\end{array}$ \\
\hline $\begin{array}{l}\text { Advertising of OTC drugs in } \\
\text { the media }\end{array}$ & Yes & Yes & Yes & Yes \\
\hline $\begin{array}{l}\text { Advertising prescription drugs } \\
\text { in the media }\end{array}$ & Yes & No & No & No \\
\hline $\begin{array}{l}\text { Recipe according to the } \\
\text { original brand-name of the } \\
\text { manufacturer }\end{array}$ & Yes & Yes & Yes & $\begin{array}{l}\text { Only } \\
\text { according to } \\
\text { the } \\
\text { international } \\
\text { name of } \\
\text { drugs }\end{array}$ \\
\hline $\begin{array}{l}\text { Advertising prescription and } \\
\text { OTC drugs in specialized } \\
\text { publications }\end{array}$ & $\begin{array}{l}\text { Yes } \\
\text { (hidden and } \\
\text { comparative } \\
\text { advertising is } \\
\text { prohibited) }\end{array}$ & $\begin{array}{c}\text { Yes } \\
\text { (hidden and } \\
\text { comparative } \\
\text { advertising is } \\
\text { prohibited) }\end{array}$ & $\begin{array}{c}\text { Yes } \\
\text { (hidden and } \\
\text { comparative } \\
\text { advertising is } \\
\text { prohibited) }\end{array}$ & $\begin{array}{c}\text { Yes } \\
\text { (hidden and } \\
\text { comparative } \\
\text { advertising is } \\
\text { prohibited) }\end{array}$ \\
\hline Providing samples of drugs & Yes & Yes & Yes & No \\
\hline $\begin{array}{l}\text { Gifts to doctors for birthday, } \\
\text { new year, day of the medical } \\
\text { worker, March } 8 \text { and February } \\
23\end{array}$ & Yes & Yes & Yes & No \\
\hline $\begin{array}{l}\text { Payment for meetings with } \\
\text { doctors in the restaurant }\end{array}$ & Yes & Yes & Yes & No \\
\hline $\begin{array}{l}\text { Souvenirs for doctors and } \\
\text { pharmacists with the company } \\
\text { or drug logo (pens and } \\
\text { notepads, tea mugs and } \\
\text { medical gone) }\end{array}$ & Yes & Yes & Yes & No \\
\hline $\begin{array}{l}\text { Payment for participation in } \\
\text { national and foreign } \\
\text { conferences }\end{array}$ & Yes & Yes & Yes & No \\
\hline $\begin{array}{l}\text { Participation in conferences } \\
\text { with leading experts, opinion } \\
\text { leaders (OL) }\end{array}$ & Yes & Yes & Yes & $\begin{array}{l}\text { Only with the } \\
\text { participation } \\
\text { of } 2 \text { or more } \\
\text { competing } \\
\text { companies }\end{array}$ \\
\hline $\begin{array}{l}\text { Visits of medical } \\
\text { representatives }\end{array}$ & Yes & Yes & Yes & $\begin{array}{c}\text { Only on agreem } \\
\text { with the } \\
\text { administration } \\
\text { hospitals }\end{array}$ \\
\hline $\begin{array}{l}\text { Sending information to doctors } \\
\text { by e-mail (on preliminary } \\
\text { agreement of doctors) }\end{array}$ & Yes & Yes & Yes & Yes \\
\hline $\begin{array}{l}\text { Collaboration with patient } \\
\text { organizations }\end{array}$ & No & No & No & Yes \\
\hline
\end{tabular}




\section{Materials and Methods}

On the pharmaceutical market of the Russian Federation in different periods of time were legally allowed different techniques of launching of innovative drugs (table 2). Recently, manufacturing companies are increasingly using digital technologies in the promotion of new drug molecules. The most commonly is the use of e-mail doctors to send promotional information messages. Digital technologies are also being actively implemented in cooperation with the patient community [7]. However, in the scientific economic literature, we have not found data on the effectiveness of digitalization of marketing activities in entering of innovative drugs to the pharmaceutical market.

We conducted an experiment among two groups of consumers (doctors and patients in the Kirov region) to determine the dependence of prescription and consumption of drugs on the use of digital technique of launching of innovative drugs to the pharmaceutical market. The study selected 30 patients with rheumatic diseases receiving innovative drugs, half of whom were trained on the problem of the disease and modern treatment at special training courses for patients organized by the doctor during the examination at the hospital - "Digital schools for patients". Then within six months this group received SMS-notifications and emails per day and on the day of taking the prescribed medications from the nurse of the regional hospital department. The remaining 15 patients did not take such educational classes and did not participate in the project. Six months after attending this training cycle, we conducted a survey of all 30 patients to calculate the number of visits to the doctor and the number of drugs purchased at the pharmacy during this period.

Table 3. Experimental data on the application of "Digital schools for patients" among patients.

\begin{tabular}{|c|c|c|c|c|c|c|c|}
\hline № & $\begin{array}{l}\text { Visitin } \\
\text { g } \\
\text { patient } \\
\text { schools } \\
\text { (1-yes, } \\
2-n o)\end{array}$ & $\begin{array}{l}\text { Number of } \\
\text { visits to the } \\
\text { doctor in } 6 \\
\text { months (1- } \\
\text { high, 2- } \\
\text { medium, 3- } \\
\text { low) }\end{array}$ & $\begin{array}{l}\text { Number of } \\
\text { drugs } \\
\text { purchased } \\
\text { at the } \\
\text { pharmacy } \\
\text { in the last } \\
6 \text { months } \\
\text { (packages) }\end{array}$ & № & $\begin{array}{l}\text { Visiting } \\
\text { patient } \\
\text { schools } \\
\text { (1-yes, 2- } \\
\text { no) }\end{array}$ & $\begin{array}{l}\text { Number } \\
\text { of visits to } \\
\text { the doctor } \\
\text { in } \\
\text { months (1 } \\
\text { - high, } 2 \text { - } \\
\text { medium, } 3 \\
\text { - low) }\end{array}$ & $\begin{array}{l}\text { Number } \\
\text { of drugs } \\
\text { purchase } \\
\text { d at the } \\
\text { pharmacy } \\
\text { in the last } \\
6 \text { months } \\
\text { (packages } \\
\text { ) }\end{array}$ \\
\hline 1 & 1 & 1 & 8 & 16 & 2 & 1 & 6 \\
\hline 2 & 1 & 1 & 6 & 17 & 2 & 1 & 6 \\
\hline 3 & 1 & 1 & 7 & 18 & 2 & 1 & 6 \\
\hline 4 & 1 & 1 & 6 & 19 & 2 & 1 & 6 \\
\hline 5 & 1 & 1 & 8 & 20 & 2 & 1 & 6 \\
\hline 6 & 1 & 2 & 6 & 21 & 2 & 2 & 5 \\
\hline 7 & 1 & 2 & 7 & 22 & 2 & 2 & 6 \\
\hline 8 & 1 & 2 & 7 & 23 & 2 & 2 & 6 \\
\hline 9 & 1 & 2 & 6 & 24 & 2 & 2 & 6 \\
\hline 10 & 1 & 2 & 6 & 25 & 2 & 2 & 6 \\
\hline 11 & 1 & 3 & 7 & 26 & 2 & 3 & 4 \\
\hline 12 & 1 & 3 & 6 & 27 & 2 & 3 & 6 \\
\hline 13 & 1 & 3 & 6 & 28 & 2 & 3 & 5 \\
\hline 14 & 1 & 3 & 8 & 29 & 2 & 3 & 6 \\
\hline 15 & 1 & 3 & 6 & 30 & 2 & 3 & 4 \\
\hline
\end{tabular}


For further analysis, we used the method of two-factor analysis of variance. As a dependent variable (predictor), the number of drugs purchased or obtained by a preferential prescription in a pharmacy over the past six months was considered. The first independent factor was passing or absence of the fact of passing of educational school for patients, the second - the number of visits to doctors for the last half-year. To assess the first factor, two types of responses were used:

1 - did not attend, 2 - attended school for patients,

for assess the second factor:

1 - one or two visits to the doctor, 2 - three or four, 3 - five or more visits (table 3 ).

At the first stage of the experiment, 15 specialists were selected in a group of doctors prescribing innovative drugs by random selection method. They read one or more educational lectures on the use of genetic engineering basic drugs for colleagues or conducted educational lectures on diseases and modern treatment with the use of these drugs among patients at specially organized schools of patients. Preparation and reading of lectures were conducted using data from the Internet and digital devices with specialized software.

At the second stage of the experiment, we calculated the number of prescriptions for innovative medications from 15 doctors who prepared lectures and 15 doctors who are not involved in this educational project. It was also estimated the number of new patients potentially in need of these drugs, which appeared at the reception for the last 6 months. The data obtained during the study are presented in table 4.

Table 4. Experimental data on the application of "Digital schools for patients" among doctors.

\begin{tabular}{|c|c|c|c|c|c|c|c|}
\hline № & $\begin{array}{c}\text { Lecture } \\
\text { (1-Yes, 2 } \\
\text { no) }\end{array}$ & $\begin{array}{c}\text { The number of } \\
\text { new patients at } \\
\text { the reception } \\
\text { for 6 months } \\
\text { (1-high, 2- } \\
\text { medium, 3-low) }\end{array}$ & $\begin{array}{l}\text { The } \\
\text { number of } \\
\text { recipes for } \\
\text { 6ronths } \\
\text { after the } \\
\text { lecturing }\end{array}$ & $\begin{array}{l}\text { Lecture } \\
\text { (1-Yes, 2 } \\
- \text { no) }\end{array}$ & $\begin{array}{l}\text { The number of } \\
\text { new patients at } \\
\text { the reception } \\
\text { for 6r months } \\
\text { (1-high, 2- } \\
\text { medium, 3-low) }\end{array}$ & $\begin{array}{l}\text { The number } \\
\text { of recipes } \\
\text { for 6 months } \\
\text { after the } \\
\text { lecturing }\end{array}$ \\
\hline 1 & 1 & 1 & 4 & 16 & 2 & 1 & 3 \\
\hline 2 & 1 & 1 & 3 & 17 & 2 & 1 & 3 \\
\hline 3 & 1 & 1 & 4 & 18 & 2 & 1 & 3 \\
\hline 4 & 1 & 1 & 4 & 19 & 2 & 1 & 2 \\
\hline 5 & 1 & 1 & 4 & 20 & 2 & 1 & 3 \\
\hline 6 & 1 & 2 & 3 & 21 & 2 & 2 & 3 \\
\hline 7 & 1 & 2 & 4 & 22 & 2 & 2 & 3 \\
\hline 8 & 1 & 2 & 3 & 23 & 2 & 2 & 2 \\
\hline 9 & 1 & 2 & 4 & 24 & 2 & 2 & 3 \\
\hline 10 & 1 & 2 & 3 & 25 & 2 & 2 & 2 \\
\hline 11 & 1 & 3 & 3 & 26 & 2 & 3 & 3 \\
\hline 12 & 1 & 3 & 4 & 27 & 2 & 3 & 1 \\
\hline 13 & 1 & 3 & 3 & 28 & 2 & 3 & 3 \\
\hline 14 & 1 & 3 & 4 & 29 & 2 & 3 & 2 \\
\hline 15 & 1 & 3 & 3 & 30 & 2 & 3 & 2 \\
\hline
\end{tabular}

For further analysis, we also used method of two-factor analysis of variance. As a dependent variable (predictor) was considered the number of prescriptions for genetically engineered drugs in the last half a year. The first independent factor was the presence or absence of the fact of lectures for colleagues and patients, the second - the number of new potential patients at the reception for the same period. To assess the first factor, two types of answers were used:

1 - participated in the preparation and reading of lectures, 2 - did not participate.

To assess the second factor, three levels of doctors ' workload were used: 
$1-1-3$ new patients, $2-3-6$ new patients, $3-7$ and more patients.

For the calculation part of the analysis we used Statistica 10 software.

\section{Results}

We conducted a two-factor discriminant analysis of the dependence of the number of purchased drugs on the number of visits to the doctor over the past six months and participation in the "digital patient school". This variance analysis is parametric, that is, it must meet the mandatory conditions for the data obtained.

The second stage of the test will evaluate the Leven test, i.e. check the difference between the variances (table 5). At $p>0.05$, the result of this test indicates that there are no differences between the variances and the use of a parametric version of the variance analysis is justified.

Table 5. Evaluation of the criterion of homogeneity of variances Levene in patients group.

\begin{tabular}{|c|c|c|c|c|}
\hline Variable & MS-effect & MS-error & $\mathrm{F}$ & $\mathrm{p}$ \\
\hline Visiting patient schools & 0.116148 & 0.1491481 & 0.777007 & 0.385563 \\
\hline $\begin{array}{c}\text { Number of visits to the } \\
\text { doctor }\end{array}$ & 0.697333 & 0.335556 & 2.078146 & 0.144725 \\
\hline
\end{tabular}

In our case, $p=0.385563$ and 0.144725 , respectively, there are no differences between the variances and the application of the analysis is appropriate.

Since all the conditions for the two-factor analysis of variance are met, we put forward three sets of hypotheses:

1. $\mathrm{H}_{\mathrm{o}}$-differences in the indicators of the effective sign due to the factor of the number of visits to the doctor over the past six months, do not significantly exceed the random differences between the indicators,

$\mathrm{H}_{1}$-differences in the indicators of the effective sign, due to the factor of the number of visits to the doctor over the past six months, significantly exceed the random differences between the indicators.

2. $\mathrm{H}_{0}$-differences in the indicators of the effective sign due to the factor of visiting the "Digital school for patients" do not significantly exceed the random differences between the indicators,

$\mathrm{H}_{1}$-differences in the indicators of the effective sign, due to the influence of the factor of visiting the "Digital school for patients", significantly exceed the random differences between the indicators.

3. $\mathrm{H}_{0}$ - influence of the factor of "digital school for patients" on the effective sign is the same for different number of visits to the doctor in the last six months and Vice versa,

$\mathrm{H}_{1}$-the influence of the factor of visiting the "Digital school for patients" on the effective sign is different with different number of visits to the doctor over the past six months and conversely.

We estimate the reliability of the influence of each of the independent factors separately and both at the same time to confirm or refute the hypotheses (table 6).

Table 6. One-dimensional criteria of significance and power of independent factors in patient group.

\begin{tabular}{|c|c|c|c|c|c|c|}
\hline Effect & SS & $\begin{array}{c}\text { Free } \\
\text { levels }\end{array}$ & MS & F & p & $\begin{array}{c}\text { Observed } \\
\text { power }\end{array}$ \\
\hline Free term & 1128.533 & 1 & 1128.533 & 2051.879 & 0.000000 & 1.000000 \\
\hline $\begin{array}{c}\text { Visiting } \\
\text { patient } \\
\text { schools }\end{array}$ & 8.533 & 1 & 8.533 & 15.515 & 0.000615 & 0.865389 \\
\hline
\end{tabular}




\begin{tabular}{|c|c|c|c|c|c|c|}
\hline $\begin{array}{c}\text { Number of } \\
\text { visits to } \\
\text { the doctor }\end{array}$ & 2.467 & 2 & 1.233 & 2.242 & 0.127988 & 0.411479 \\
\hline $\begin{array}{c}\text { Number of } \\
\text { visits and } \\
\text { school } \\
\text { attendance }\end{array}$ & 1.267 & 2 & 0.633 & 1.152 & 0.333016 & 0.228816 \\
\hline Error & 13.200 & 24 & 0.550 & & & \\
\hline
\end{tabular}

As follows from the tabular data, the reliability of $p<0.05$ was revealed only in one separate factor - a visit to the "Digital school for patients". Thus, only one hypothesis about the reliability was confirmed - the differences in the indicators of the effective sign due to the action of the factor of visiting the "Digital school for patients" significantly exceed the random differences between these indicators. The influence of the number of visits to the doctor in the last six months and the combined effect of both factors were statistically unreliable. This conclusion can be explained by the fact that not every visit to the doctor leads to a prescription and purchase of medicines in the pharmacy.

When assessing the degree of influence of a factor on the effective feature, we consider the data from the column "Observed power", which in our experiment ranges from $22.88 \%$ to $86.53 \%$. Taking into account the reliability of each of the signs, we can only consider the influence of the factor of visiting the "digital school for patients", which significantly increases the number of drugs purchased or obtained by preferential prescription in the pharmacy over the past six months.

We also conducted a two-factor discriminant analysis of the dependence of the number of prescriptions for innovative drugs on the identification of new potential patients and participation in the experiment of the "Digital school for patients". This variant of the analysis of variance under consideration is parametric, that is, it must satisfy some mandatory conditions with respect to the data obtained. First, the values of the analyzed trait in each of the compared groups should be distributed normally, secondly, there should be no statistically significant difference between the variances, that is, they should be homogeneous, third, all compared samples should be independent of each other.

Check the difference between the variances, for this estimate the Leven test (table 7). At $p>0.05$, the result of this test indicates that there are no differences between the variances and the use of a parametric version of the variance analysis is justified.

Table 7. Evaluation of the criterion of homogeneity of variances Levene in doctors group.

\begin{tabular}{|c|c|c|c|c|}
\hline Variable & MS-effect & MS-error & $\mathbf{F}$ & $\mathbf{p}$ \\
\hline New patients & 1.197333 & 0.234815 & 0.840379 & 0.442525 \\
\hline Lecture reading & 0.029037 & 0.037354 & 0.777337 & 0.385463 \\
\hline
\end{tabular}

In our case, $p=0.442525$ and 0.385463 , respectively, there are no differences between the variances and the application of the analysis is appropriate.

Since all the conditions for the two-factor analysis of variance are met, we put forward three sets of hypotheses:

1. $\mathrm{H}_{0}$-differences in the indicators of the effective sign due to the action of the factor of appearance of new potential patients do not significantly exceed the random differences between the indicators,

$\mathrm{H}_{1}$-differences in the indicators of the effective sign, due to the action of the factor of the emergence of new potential patients, significantly exceed the random differences between the indicators. 
2. $\mathrm{H}_{0}$-differences in the indicators of the effective sign due to the factor of participation in the "Digital school for patients" do not significantly exceed the random differences between the indicators,

$\mathrm{H}_{1}$-differences in the indicators of the effective sign due to the factor of participation in the "Digital school for patients" significantly exceed the random differences between the indicators.

3. $\mathrm{H}_{0}$ - the influence of the factor of participation in the "Digital school for patients" on the effective sign is the same when a different number of new potential patients appear and Vice versa,

$\mathrm{H}_{1}$-the influence of the factor of participation in the" Digital school for patients " on the effective sign is different when a different number of new potential patients appear and conversely.

To confirm or refute the hypotheses put forward, we estimate the reliability of the influence of each of the independent factors separately and both at the same time (table 8).

Table 8. One-dimensional criteria of significance and power of independent factors in doctors group.

\begin{tabular}{|c|c|c|c|c|c|c|}
\hline Effect & SS & $\begin{array}{c}\text { Free } \\
\text { levels }\end{array}$ & MS & F & p & $\begin{array}{c}\text { Observed } \\
\text { power }\end{array}$ \\
\hline Free term & 276.0333 & 1 & 276.0333 & 828.1000 & 0.000000 & 1.000000 \\
\hline $\begin{array}{c}\text { New } \\
\text { patients }\end{array}$ & 1.2667 & 2 & 0.6333 & 1.9000 & 0.171395 & 0.355201 \\
\hline $\begin{array}{c}\text { Lecture } \\
\text { reading }\end{array}$ & 7.5000 & 1 & 7.5000 & 22.5000 & 0.024390 & 0.905151 \\
\hline $\begin{array}{c}\text { New } \\
\text { patients } \\
\text { and lecture } \\
\text { reading }\end{array}$ & 0.2000 & 2 & 0.1000 & 0.3000 & 0.483871 & 0.092138 \\
\hline Error & 8.0000 & 24 & 0.3333 & & & \\
\hline
\end{tabular}

As can be seen from the table data, the reliability of $p<0.05$ in only one single factorparticipation in the "Digital school for patients". Thus, only one hypothesis about the reliability was confirmed-the differences in the indicators of the effective sign due to the action of the factor of participation in the "Digital school for patients" significantly exceed the random differences between these indicators. The influence of the factor of appearance of new patients and the joint influence of both factors was statistically unreliable.

When assessing the degree of influence of a factor on the effective feature, we consider the data from the column "Observed power", which in our experiment ranges from $35.52 \%$ to $90.51 \%$. However, these rather large values should be considered taking into account the reliability of each of the features.

Thus, lecturing on the problem of the disease for colleagues and at the "Digital school for patients" significantly increases the number of prescribed innovative drugs, and the power of this effect is $90.51 \%$.

\section{Discussion}

Marketing activity of manufacturing companies in the pharmaceutical market of the Russian Federation is legally limited. In this regard, methods of launching of innovative drugs require constant development [8]. One of the areas of improvement is the use of digital technologies [9]. According to a survey of Russian and foreign pharmaceutical companies, most of them have implemented or are planning to implement digital business optimization tools (figure $1)$. 


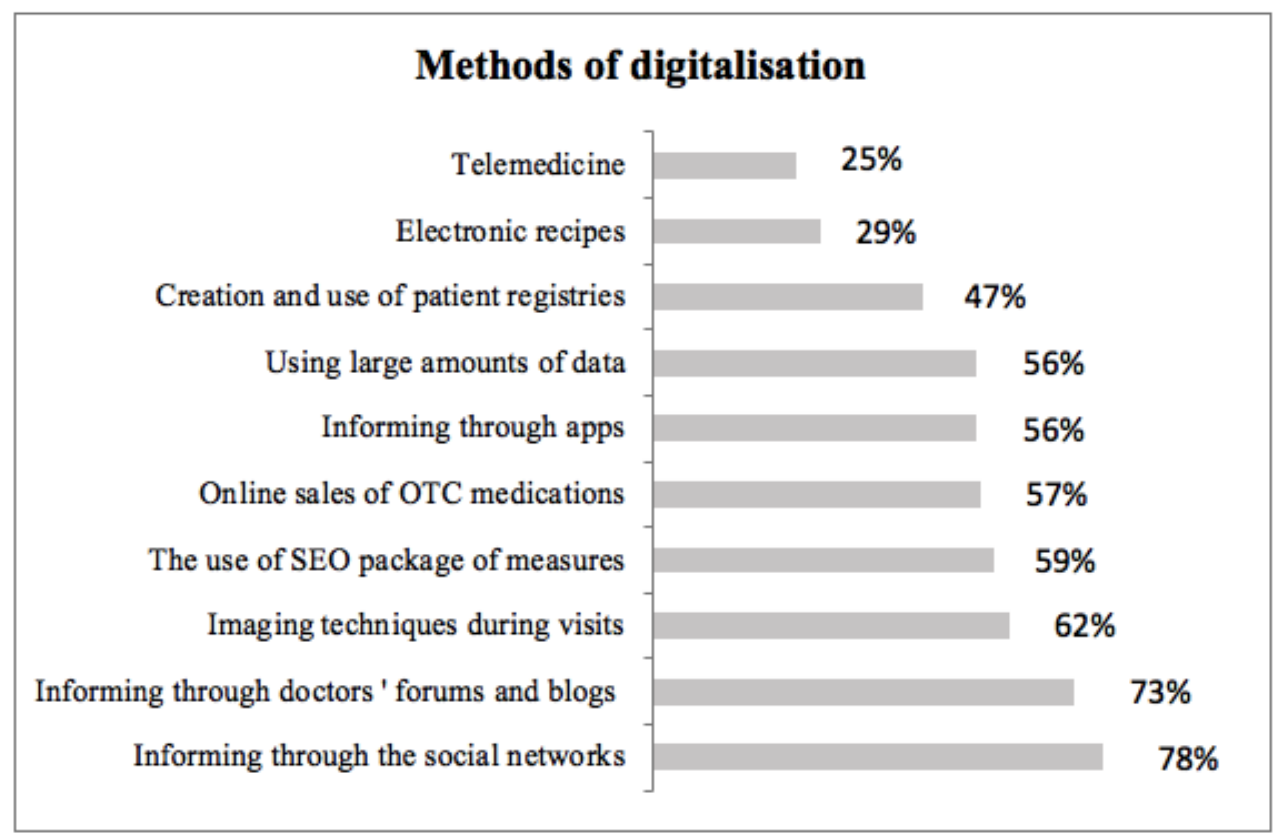

Fig.1. Current digital tools of launching of innovative medicines to the Russian pharmaceutical market.

The most popular solution in the pharmaceutical industry is to inform about new products on the official website, through the pages in social networks and forums of the medical community [10]. In addition to the publication of instructions on the use of medicines, clinical trial data on efficacy and safety are available. These methods of digitalization are used by more than $73 \%$ of respondents.

The traditional method of launching of innovative drugs to the pharmaceutical market is the visit of a medical representative. However, in recent years, in contact with the doctor uses a variety of electronic devices to visualize the information in the form of tables, graphs and drawings. $62 \%$ of companies use this method.

Most pharmaceutical companies (59\%) use a set of measures for internal and external optimization to raise the position of the site in the results of search engines for certain user requests (SEO-complex). The processing of large data sets according to various criteria is also used to predict and determine the target audience in $56 \%$ of cases.

Telemedicine and the introduction of electronic prescriptions is a national task. Pharmaceutical companies are already using these methods of launching of innovative drug molecules. Online remote consultations and lectures of leading specialists are used by $25 \%$ of respondents.

Recently, the method of creating electronic patient registers for certain diseases $(47 \%)$ and informing through electronic applications $(56 \%)$ has been increasingly used. Of course, the active use of digital technologies is a stage in the development of society. However, the economic essence of the activities of commercial companies requires clear calculations of the cost effectiveness incurred on the implementation and development of digital methods of business optimization.

We conducted a study that revealed the dependence of prescription and consumption of drugs on the use of digital tools of launching of innovative drugs to the pharmaceutical market. The use of digitalization has proved to be significantly effective both among doctors 
and patients, which makes it possible to recommend the use of "Digital schools for patients" in the marketing activity of pharmaceutical companies.

\section{Conclusions}

The active introduction of digital tools of launching of innovative medications to the pharmaceutical market is one of the main tasks for manufacturing companies. The use of digitization elements allows for faster exchange of information between the consumer and the producer, which leads to better planning and forecasting of commercial activities.

According to our investigations, participation in "Digital schools for patients" significantly increase the consumption of medicines among patients, and the preparation and reading of lectures in this project lead to an increase in prescriptions among doctors. These results allow us to recommend the further introduction of digitalization in entering of innovative drugs to the pharmaceutical market.

\section{References}

1. D. Payne, British Medical Journal, 353 (2016) doi.org/10.1136/bmj.i2896

2. G. Iacobucci, British Medical Journal, 362 (2018) doi.org/10.1136/bmj.k3861

3. H. Salisbury, British Medical Journal, 364 (2019) doi.org/10.1136/bmj.11091

4. A. Gulland, British Medical Journal, 359 (2017) doi.org/10.1136/bmj.j5365

5. W. Gellad, A. Kesselheim, New England Journal of Medicine, 376, 2001-2004 (2017) doi.org/10.1056/NEJMp1700446

6. G. Elwyn, P. Barr, S. Piper, British Medical Journal, 361 (2018) doi.org/10.1136/bmj.k2061.S

7. J. Gruman, M. Rovner, M. French, Patient Education and Counseling, 78, 350-356 (2010) doi.org/10.1016/j.pec.2010.02.002

8. S. Chimonas, N. Rosario, D. Rothman, Health Services Research, 45(1), 98-114 (2010) doi.org/10.1111/j.1475-6773.2009.01048.x

9. H. Taiminen, H. Karjaluoto, Journal of Small Business and Enterprise Development, 22(4), 633-651 (2010) doi.org/10.1108/JSBED-05-2013-0073

10. T. Mackey, B. Liang, Globalization and Health, 10 (2013) doi.org/10.1186/1744-86039-45 